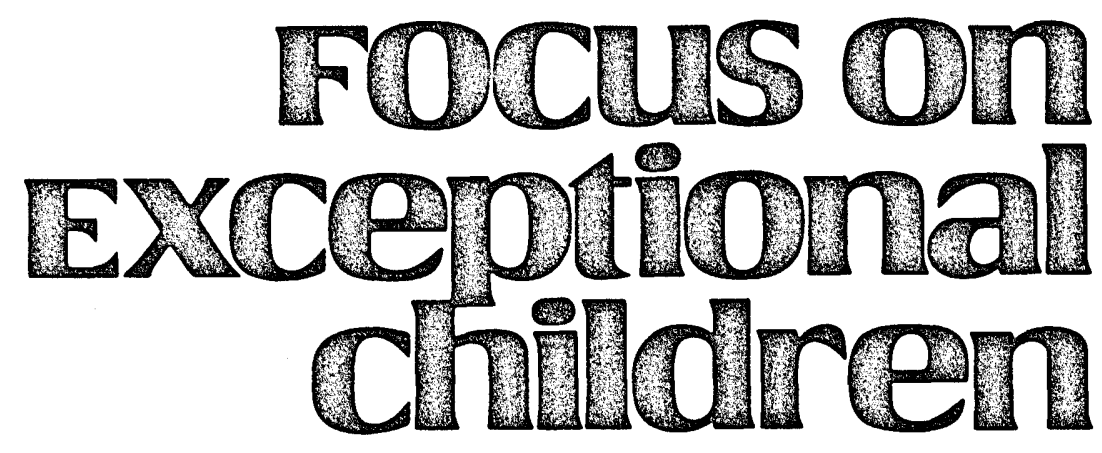

\title{
A Collaborative Model for Students with Mild Disabilities in Middle Schools
}

\author{
Alan E. White and Lynda L. White
}

The Individuals with Disabilities Education Act of 1990 (PL 101-476) and implementing regulations are responsible for shifting students with disabilities from one educational setting to another. Earlier efforts had been aimed at serving students with disabilities in special programs as a part of the public schools but not necessarily with general education students. This was followed by a movement to establish all programs for special students on the general education campus. Educators also identified and classified more students with mild disabilities and moved them from regular classes into special education resource classrooms. Approximately 15 years elapsed before Americans came to understand that what is really needed for many students with disabilities is to place them back into a more normalized regular classroom setting and educate them with their nondisabled peers.

This movement is not that unusual. The simple recognition of a need to help students with disabilities in school has always been an underlying theme of special education, and no one could argue with that idea. It seems, however, that we have been quite guilty of trying to educate those with disabilities by moving them away from the regular curriculum via a separate special education track. In doing so, we have succeeded in isolating the students physically and socially and have severely limited their opportunity for exposure to the established regular education curriculum. This is especially true for students with mild learning disabilities, behavior/emotional disorders, and intellectual disabilities.

\section{BACKGROUND}

Over many years, the pull-out delivery of service was the mainstay of school programs for the majority of students with disabilities. Large numbers of programs for the gifted, remedial, and non-English speaking students also employed this model. This delivery system has come under scrutiny as a result of policy, litigation, and research in special education. Wang and Baker (1986) and Wang and Zollers (1990), for example, demonstrated the educational benefit of participation in regular classes. The investigations of Stainback and Stainback $(1989,1990)$ also provide clear indicators for inclusive educational approaches.

Alan White is Director of Special Services for the Marietta City School District, Marietta, Georgia. Lynda White is Supervisor, Special Education Department, for the Cobb County School District, Marietta, Georgia.

(C) Love Publishing Company, 1992. 
The efficacy of interaction with nondisabled peers in a regular class setting is now fortified by a more practical need for comparable instruction in curriculum content for students with disabilities. Likewise, attention to learning styles, behavioral strategies, augmentive communication, and motivational techniques are examples of special education instruction that can take place in the regular education classroom.

Designing and implementing an instructional model for integrating students with disabilities into the regular classroom setting is a process of defining and redefining the requirements of the least restrictive environment under the Individuals with Disabilities Education Act (IDEA). Models that broadly fall into this concept are those of collaborative teaching, team teaching, inclusion, pull-in, and similar terminology used to describe integrated instructional procedures. The emphasis on joint efforts by general and special education is found more often at the secondary level but is becoming increasingly accepted as appropriate for middle and elementary age groups as well.

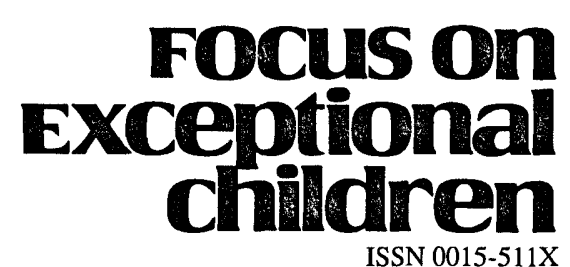
FOCUS ON EXCEPTIONAL CHILDREN (USPS 203-360) is published monthly except June, July, and August as a service to teachers, special educators, curriculum specialists, administrators, and those concerned with the special education of exceptional children. This publication is annotated and indexed by the ERIC Clearinghouse on Handicapped and Gifted Children for publication in the monthly Current Index to Journals in Education (CIJE) and the quarterly index, Exceptional Children Education Resources (ECER). It is also available in microfilm from Xerox University Microfilms, Ann Arbor, MI. Subscription rates: Individual, \$27 per year; institutions, $\$ 36$ per year. Copyright (C) 1992, Love Publishing Company. All rights reserved. Reproduction in whole or part without written permission is prohibited. Printed in the United States of America. Second class postage is paid at Denver, Colorado. POSTMASTER: Send address changes to:

$$
\begin{aligned}
& \text { Love Publishing Company } \\
& \text { Executive and Editorial Office } \\
& 1777 \text { South Bellaire Street } \\
& \text { Denver, Colorado } 80222 \\
& \text { Telephone (303) 757-2579 }
\end{aligned}
$$

Edward L. Meyen

University of Kansas

Richard J. Whelan

University of Kansas Medical Center
Holly T. Rumpler Senior Editor
Many states and local school systems have developed required curriculum content for middle school students, designed to meet the unique learning needs of students in grades six through eight. The delivery of services for special education students in these grades, however, has not been modified at the same pace as the changing national emphasis on the middle school learner. In many instances, the traditional pull-out program of elementary school special education continues into the middle school program. Nevertheless, the middle school team approach by grade level and the instructional design for each specific grade level form a ready foundation for implementing the collaborative or team-teaching efforts of regular and special education students.

The purpose of this article is not to try to convince educators of the need of instructing students with disabilities in regular classes. A significant body of information already exists in research, law, and policy, plus common sense, that not only supports but actually demands that we offer similar educational opportunity to disabled and nondisabled students alike. Rather, we present a systematic approach for implementing a middle school collaborative model for the delivery of service to students with mild disabilities.

\section{AN OVERVIEW}

Various terms have been used to describe a combined instructional model for general and special education. In this article, collaboration refers to a single classroom combining disabled and nondisabled students, with instruction by one special education teacher and one general education teacher. The model for collaborative special and regular educational instruction is applicable to the high school and elementary levels, but the discussion here is directed specifically to the middle school level.

Students entering the sixth through eighth grades are well suited for the collaborative teaching model. The separation of students by grade and, more important, the emphasis on instructional teaming at the middle school level provide a ready avenue for collaborative teaching.

\section{COMPONENTS OF THE MODEL}

Major components of the model are denoted in Figure 1.

\section{Program Design}

Some school systems may not begin the collaborative teaching effort without a systemwide adoption of instructional philosophy for all special education programs. Deci- 


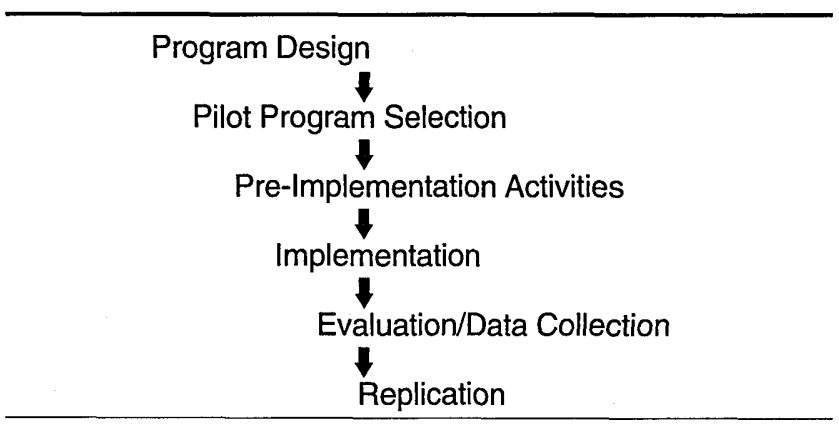

\section{FIGURE 1 \\ Major Components of the Collaborative Teaching Model}

sions should be made with regard to the issues of inclusion and the regular education initiative positions, such as those expressed by Will (1986), Lilly (1986), or of Hallahan, Keller, McKinney, Lloyd, and Bryan (1988). Villa and Thousand (1990) provide strategies to promote a system philosophy for including special education students in the regular education mainstream. It is recommended that systems first demonstrate success of the program by establishing one or more pilot projects.

However the system chooses to approach initial implementation, the program philosophy and program design must be the result of joint regular and special education decision making. Special education staff cannot hope to implement a collaborative teaching model together with regular education instruction without advance planning, discussion, and agreement with system-level curriculum personnel.

\section{Pilot Program Selection}

Prior to implementing a model for delivery of services to students with mild disabilities, school districts may choose to identify a pilot site. School districts with small student enrollments might target one class or one grade in a school. Larger districts with several middle schools may select more than one school for participation during the initial implementation year. We do suggest that the number of pilot sites be limited because of the significant impact of staff training and data collection. Working through problems on a small scale during the first year allows orderly expansion later on.

\section{Site Pre-Selection Activities}

Prior to selecting the site, information should be gathered and reviewed to determine potential success of the model in a specific school. Types of information to be considered may include:
1. Local school administrative support

-Does the school principal support the concept of collaborative teaching?

-Will the model receive the necessary attention during development of the school's master schedule?

- Can the regular and special education teachers have common planning time?

-Will the model have support of parents and the community?

-Will the principal support the school's selection as a pilot site?

2. Local school teacher support

-Do special and regular education teachers support the philosophy of collaboration?

- Are both groups willing to plan, provide instruction, and evaluate student performance collectively?

-Is there potential for a positive "match" of regular and special education teachers?

- Are both groups open to change as it relates to the instructional process?

- Are there teachers with similar classroom behavior management strategies?

- Are there teachers who have demonstrated the ability to share teaching responsibilities and to work together effectively?

- Can teachers collectively plan for positive parent involvement?

-Will teachers be returning to the school the following year?

-Does the school have more than one special education teacher?

-Are there teachers who are willing to participate in data collection activities?

3. Special education student information

- What data are available on special education students by area of disability and by grade level?

A data grid such as that presented in Figure 2 may assist school staff in gathering information regarding the number of students and periods per day of service as required in the students' IEPs. The maximum number of students served during each instructional period may be restricted by state or local regulations. The format of the grid, however, may be useful in identifying a group of students with common disabilities and grade levels. An appropriate number of students with the same grade placement and similar IEP goals and objectives could constitute a potential group for collaborative teaching. 


\begin{tabular}{|c|c|c|c|}
\hline & No. of S & idents/No. & Periods \\
\hline & 6th Grade & 7th Grade & 8th Grade \\
\hline $\begin{array}{l}\text { Learning } \\
\text { Disabilities }\end{array}$ & & & \\
\hline $\begin{array}{l}\text { Emotional/Beha } \\
\text { Disorders }\end{array}$ & & & \\
\hline $\begin{array}{l}\text { Mild Intellectual } \\
\text { Disabilities }\end{array}$ & & & \\
\hline
\end{tabular}

FIGURE 2

Site Selection Data Grid

Data collected might reflect, for example, that eight learning disabled students in the seventh grade have IEP goals and objectives focusing on the broad areas of reading comprehension and written expression skills. If the IEPs of these same students recommend two periods per day in special education, the eight special education students could be scheduled into a regular class for the determined curricula area. In addition, if collaborative opportunities exist, IEPs can be modified according to due process to allow more participation of special education students in a general education classroom.

\section{Pilot Site Selection}

Once data on potential sites have been collected, a review by special and regular education administration is recommended. Sites are rated as to potential effectiveness for a pi- lot program, followed by a final determination of sites. The local schools are officially contacted and their willingness to participate is confirmed.

\section{Pre-Implementation Activities}

\section{Teacher Selection}

After pilot sites have been selected, the participating teachers should be identified. According to Stalvey, Dye, and Goldblatt (1985), the most critical factor for pilot success is the selection and match of teachers involved. White, Spurgeon, Jackson, and Green-Folks (1991) suggest that selection criteria be based on:

- common interest and willingness to participate in collaborative teaching.

- established relationships between regular and special educators in the school.

— similar behavior management strategies.

- ability to share responsibilities of planning, presenting instruction, and evaluating students.

- demonstration of a plan for positive parent involvement.

Actual selection of a teacher team may occur formally or informally. A formal method suggested in Figure 3 by White et al. (1991) may utilize a teacher survey to assess attitudes toward collaborative teaching. Several other inventories are

Teacher

A collaborative teacher will:

1. Provide increased effective interaction among regular and special education teachers.

2. Work to improve student self-esteem.

3. Increase teacher/student awareness of individual differences.

4. Provide lower teacher/pupil ratios.

5. Provide for intensive interdisciplinary common planning.

6. Allow for students to problem-solve and improve selfmanagement skills.

7. Allow for more flexibility in scheduling.

8. Provide for generalization and transfer of learning strategies.

9. Provide for cooperative learning experiences.

10. Provide exposure to an increased awareness of regular education curriculum.

From Cobb County School District, Cobb County, Georgia. 
available for assessment, such as the Learning Styles Inventory (Silver \& Hanson, 1980). The informal method, more feasible in most instances, consists of a meeting of interested teachers to discuss possibilities, interest in the model, and their ability to work together as a team. Even though formal instruments and inventories are useful, the most crucial issue is the willingness and commitment of teachers to work together in teams. Determination of teachers' characteristics, whether by formal or by informal means, is necessary to insure success. The pilot site should begin with one selected team for initial implementation.

\section{Student Selection and Scheduling}

Information on number of students, categories of disability, periods of service, and IEP goals and objectives should be available from data gathered during the site selection stage. The co-teaching team reviews the data and identifies the largest group of students in the same grade and with similar IEP goals and objectives. Table 1 presents data on a middle school that serves 60 resource students with mild disabilities through special education.

\begin{tabular}{lrrr}
\hline \multicolumn{5}{c}{ TABLE 1 } \\
Example Middle School Data \\
Area of disability & 6 th & 7th & 8th \\
Learning Disabled & 10 & 12 & 12 \\
Emotional/Behavioral & 5 & 7 & 7 \\
Mild Intellectual & 3 & 2 & 2 \\
\hline
\end{tabular}

In this scenario, review of the data may reveal that of the sixth-grade LD students, eight have IEP goals in the language arts area and two students have goals for math. Then a sixth-grade language arts group could be considered for coteaching. Selection of the students might be limited to the grade level taught by teachers participating in the pilot. If an eighth-grade language arts teacher is a willing participant, the co-teaching team would review and select appropriate eighth-grade students.

When selecting students, other considerations are:

1. Prior success in a regular education setting.

2. Student success in other cooperative learning situations

3. Consideration of class content and student IEP objectives.

4. The degree of student behavior management required.

Students who do not meet these criteria may not be selected and thus continue to receive services through the tradi- tional resource model. When all considerations have been applied to individual students, the team can determine the final group for inclusion in the collaborative teaching class. The school schedule then should include this group of students in the class. In many instances the pilot group is scheduled first to avoid difficult and often unpopular schedule changes later.

\section{Parent Notification}

Parents of students participating in the pilot should be included in the planning process. This may be done through an announced group meeting of parents with students who are considered for the model. Also, IEP meetings can be usedor may be required if the amount of time in special education or goals and objectives are to be modified. If the amount of time or goals and objectives remain the same, a less formal meeting or discussion may be held with the parents.

The special education administrators should review local due process procedures to assure that all requirements of the system are maintained. Regardless of the procedure, parents should be informed of the background, philosophy, and procedures to be used in the collaborative model. The increased participation with nondisabled students should be approached in a positive manner. Hanline and Halvorsen (1989) indicate that parental involvement during this transitional process is important to success.

\section{Staff Training}

Teachers participating in the collaborative model also must be assisted in adjusting to the change, because implementing the model is an ongoing process that is not limited to a single event. Staff training for co-teachers must occur prior to implementation of the model. Even though training activities often focus on routine tasks such as timelines, data collection, and the like, a significant amount of time in the initial training session should center on changing certain mindsets or paradigms (“. . . because that's the way it's always been done") and stressing the importance of sharing and working together.

If more than one school is involved, all participating teachers and administrators can be trained at the same time, although teacher teams should participate in activities together. Bonding activities and simulations proved successful in districts such as the Cobb County School District, Georgia, where collaborative models are in place. Communication is the key to successful collaborative teaching and activities that build rapport and strengthen communication are critical, during initial implementation as well as throughout the entire 
pilot phase. Initial training should provide teachers with a repertoire of communication strategies that will help them get started as a team and serve as a resource if communication issues develop later.

\section{Implementation}

\section{The Instructional Process}

The goal of instruction is student performance and achievement.

In a two-year study by the National Association of State Boards of Education, Roach (1991) reported:

\begin{abstract}
States are exploring "outcome-based" education. They are shifting the focus away from processes and "input" measures such as the number of textbooks in a school and types of courses offered. Instead, there is an interest in performance, achievement, and "outcome" measures such as student knowledge and skills, student participation in social experiences, student participation in community and school life, and student satisfaction.

The "model" chosen for instruction should address all these areas. In the collaborative teaching model, the regular and special education teachers share responsibility of the instructional process by jointly planning, presenting and evaluating the instruction.
\end{abstract}

\section{Planning Phase}

Planning for instruction is vital to instructional effectiveness. Common planning time should be scheduled for both teachers in the collaborative model. Administrative support is required to allow for this planning time in the schedule. During the planning phase, the general education teacher responsible for content pinpoints the concepts and material to be taught. The special education teacher suggests various modes and forms of presenting the information (Stalvey et al., 1985). Special educators bring to the team specialized skills in the areas of diagnosis and assessment, individualized instruction, and classroom management. The general educator's knowledge of course content for middle school curricular areas provides the foundation for instruction. Planning emphasizes not only what is to be taught in content but also how it is to be taught employing various methodologies.

Included in the planning phase is joint decision making by both teachers regarding the method for evaluating instructional lessons. Among various evaluative considerations are completion of assignments, earning daily points, turning in homework, class projects, and participation in cooperative learning activities. For example, both teachers may agree on the use of an assignment notebook to address the improvement of organizational skills. The planning encompasses the needs of all disabled and nondisabled students.

Planning time also provides the opportunity to review daily, weekly, or other results of student performance. The development, scoring, and weighting of tests and other assessment measures should be agreed upon jointly as part of the district's required grading procedures. Consideration and completion of final grades is a shared effort for all students in the class.

\section{Instructional Phase}

Lesson presentation is a responsibility of both teachers. This process has to be shared to prevent one teacher from becoming subordinate to the other. Students should not be given the impression that one assumes the role of "teacher" and one of "helper." Shifting of leadership in lesson presentation prevents negative role patterns from developing.

Lesson presentation can be shared using techniques such as the following.

1. The general education teacher presents new information to the class. The special education teacher writes notes on the chalkboard for students to copy. At the conclusion of the presentation, the special education teacher reviews the main points of the lesson from the chalkboard and leads class discussion.

2. The special education teacher organizes students into cooperative learning groups and presents an activity or assignment for each group to complete. Both teachers move about the room and answer questions, providing assistance to the groups as they work. When work is complete, groups share their work with the class as both teachers provide feedback.

3. Both teachers, prior to a test, have planned and developed questions for a competition as a study session, using a Jeopardy format. The special education teacher serves as the moderator, covers the rules, and conducts the game. The general education teacher serves as timeand-score keeper and conducts a summary review at the end of the game.

4. Both teachers assist students in developing organizational skills through the use of individual student notebooks. Both teachers direct disabled and nondisabled students through a process that may include: maintaining weekly logs by outlining daily required topics or is- 
sues and properly placing them in an appropriate section. Teachers share in a weekly notebook check of all students to maintain current and useful study guides.

Classroom management is the responsibility of both teachers. Each teacher shares the responsibility for modeling behavior, intervening in situations of inappropriate behavior, and planning strategies to assure a team approach in maintaining an orderly classroom. Again, advance planning and agreement on behavioral approaches is necessary to create a positive learning environment.

Presentation of facts to be learned does not assure mastery by all students. Presentation of concepts accompanied by study sheets, highlighted textbooks, color coding, clear directions, tips on how to identify main ideas, and multimodality approaches make the content meaningful. Although each of these methods may be found in a classroom, it is essential to select methodology that matches what students are to learn with how they learn. The excitement of learning will be maintained in this model as teachers identify their own individual talents, talents of the teaching team, and talents of individual students in the class.

Instructionally, collaborative teaching involves planning, presenting, and evaluating by both teachers. The interaction of curriculum content and specialized methodology presented in Figure 4 is the significant characteristic that makes this model unique. The strengths of both regular and special education are shared during a common classroom period to produce what can be a more effective instructional opportunity through collaborative teaching.

\section{Evaluation and Data Collection}

School districts implementing the collaborative teaching model should evaluate its effectiveness in a number of areas. The main focus should be on student outcomes, but additional feedback from teachers, administrators, and parents should be considered as well. Progress in academic areas should be assessed by reviewing mastery of IEP goals and objectives and final reported grades. Homework, class participation, organization skills, and other areas also should be included in the review of progress for all students in the program. Additional data should be assessed for student attitudes toward participation in the pilot.

\section{Individualized Education Program}

For students with disabilities, objectives mastered should be reviewed at the end of the pilot or during the routine annual IEP review. A data collection form should be kept for each student, reflecting the IEP objectives. These data can be summarized at the conclusion of the pilot. Prior to beginning the pilot program, the IEP committee should establish an expected percentage of mastery of goals by students with disabilities.

\section{Report Cards}

Data from report cards should be reviewed for each student in the pilot and should not be limited to a single grade in the pilot class. Each of the academic, social, organizational skills, and other areas should be included for review and comparison. The kind and type of data available on report

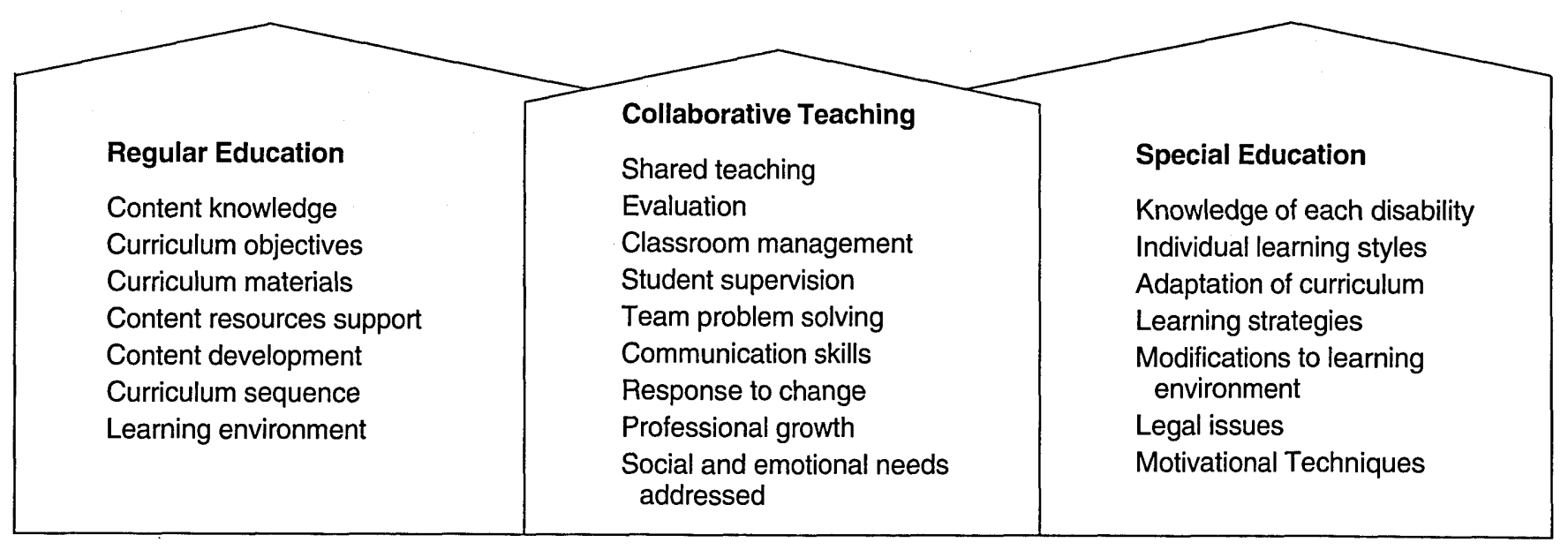


cards may differ between school systems, and identification and selection of data to be reviewed should be decided prior to implementation.

\section{Student Attitudes}

Pre- and post-assessment of student attitudes should be included as a data collection component. An initial student survey should be administered during the first two weeks and again during the final two weeks of the pilot term. Survey topics might include student attitudes toward having two teachers in one classroom, interest in the subject area, preference toward being in a regular, resource, or collaborative classroom, opinion of school, desire to participate in class, and willingness to work with other students. Topics should be assessed for both the disabled and nondisabled students in the class. A summary of the survey should be reviewed for the entire class and by each subgroup.

\section{Teacher Attitudes}

Attitudes of the teachers involved should be recorded throughout the pilot period. The pilot coordinator or other appropriate staff member should record responses to questions during the informal discussion and feedback sessions. Classroom observations and discussions should be maintained for review. The assessment of teacher attitudes might include opinions of perceived success or failure in providing curriculum content, increased learning for all students involved, student discipline, team efforts, and grading procedures, for example.

\section{Administrator Attitudes}

The school principal and other building administrators should be interviewed to assess the leadership perception of the collaborative model pilot. Central office administrators in both regular and special education also should observe the class and be interviewed. Administrative staff members should give their opinion of the program's strengths and weaknesses, along with specific suggestions and comments. The pilot coordinator should summarize all the information gained from the administrative assessment.

\section{Parent Survey}

One of the most important data collection aspects is the perception of parents regarding success of the pilot program. Their feedback is necessary to indicate if their child's IEP needs are being met through collaborative teaching and whether they have observed changes in their child's behav- ior. In some cases, parents are able to compare the child's attitude toward school, the pilot class, and instruction between team teaching and the traditional resource or pull-out model. The parent questionnaire provided in Figure 5 may be used to summarize parental opinion as part of the data collection effort.

The pilot program coordinator and other involved administrators should analyze all of the data collected to determine the effectiveness of the collaborative teaching class. Review of the data should be a group process designed to arrive at specific implications and decision making for continuation and modification of the collaborative approach.

\section{Pilot Replication}

Decisions regarding the success of a pilot class may result in consideration to expand or replicate the pilot at additional sites. The data collection process and decision making regarding the data should lead to the replication decision. Systems typically add one or two programs at a time, depending on the overall size of the district. Expansion of the program should be made through the step-by-step procedure used in the pilot.

\section{SUMMARY}

The collaborative teaching model was designed as an alternative to the traditional resource, or pull-out, model for serving students with mild disabilities. Development of a middle school model should include consideration of opinions and concerns of teachers, administrators, parents, and students. The message seems clear that we can maintain instructional integrity for students with and without disabilities through a model that teaches both groups at the same time, in the same room. A collaborative teaching model also should be considered for other age groups of disabled students and, because the model's instructional planning and strategies may be appropriate, it can be applied to at-risk populations as well.

Collaborative teaching should be viewed as an arrangement between specialists in content and methodology that delivers the strengths of both special and general education within a single instructional setting. Stalvey et al. (1985) described a ripple effect as an incidental advantage of co-teaching. One teacher's strategy is observed by another, who uses it in a different setting, where it is observed by another teacher, and so on. A similar effect has been noted in students, who experience success from observing a learning 
Parent Name

School

Student Name

Date

Please circle your response:

1. My child's participation in the collaborative teaching project:
a. had a positive effect on my child.
b. was not a positive experience for my child.
c. did not seem to be very different from previous years.

2. Do you think the collaborative teaching project helped your child to be more successful in other subjects?
a. Yes, it helped in other subjects.
b. No, it did not help.
c. I am not sure if it made a difference.

3. How do you think your child responded to the collaborative teaching project?
a. preferred having the special education teacher come into the regular classroom.
b. preferred leaving the regular classroom to go into the special education resource room.
c. does not seem to have a preference.

4. Academically, I believe my child has:
a. made more progress this year.
b. made less progress this year.
c. made about the same progress as in previous years.

5. Behaviorally, I believe my child has:
a. made more progress this year.
b. made less progress this year.
c. made about the same progress as in previous years.

6. Please complete the following statements:

a. My child would rather be in a collaborative teaching class because

b. My child would rather be in a special resource class because

c. I also would like to comment or suggest that: 
strategy from another student, who uses it later, and so on. This exchange happens again and again because teachers and students take advantage of learning events that work in producing success.

Finally, we recognize that the collaborative model should not be considered as the best and only way to provide instruction. Some students will continue to be best served through a pull-out model to meet their individual learning needs. We are suggesting, however, that using the collaborative model at the middle school level significantly expands learning opportunities for many different types of students when they are educated together.

\section{REFERENCES}

Hallahan, D. P., Keller, C. E., McKinney, J. D., Lloyd, J. W., \& Bryan, T. (1988). Examining the research base of the regular education initiative: Efficacy studies and the adaptive learning environments model. Journal of Learning Disabilities, 21, 29-34.

Hanline, M. R., \& Halvorsen, A. (1989). Parent perceptions of the integration transition process: Overcoming artificial barriers. Exceptional Children, 55, 487-492.

Lilly, M. S. (1986). The relationship between general and special education: A new face on an old issue. Counterpoint, 6, 10.
Roach, V. (1991). Special education: New questions in an era of reform. Issues in Brief (National Association of State Boards of Education) 11, 1-7.

Silver, H. F., \& Hanson, J. R. (1980). The TLC learning style inventory. Moorestown, NY: Hanson Silver \& Associates.

Stainback, S., \& Stainback, W. (Eds.). (1990). Support networks for inclusive schooling-Interdependent integrated education. Baltimore: Paul H. Brookes.

Stainback, S., Stainback, W., \& Forest, M. (Eds.). (1989). Educating all students in the mainstream of regular education. Baltimore: Paul $\mathrm{H}$. Brookes.

Stalvey, K., Dye, B., \& Goldblatt, J. (1985). Team teaching: A resource guide. Cobb County, GA: Cobb County School District.

Villa, R., \& Thousand, J. (1990). Administrative supports to promote inclusive schooling. In S. Stainback \& W. Stainback (Eds.), Support networks for inclusive schooling-Interdependent integrated education (pp. 201-218). Baltimore: Paul H. Brookes.

Wang, M. C. \& Baker, E. T. (1986). Mainstreaming programs: Design features and effects. Journal of Special Education, 19, 503-521.

Wang, M. C. \& Zollers, N. (1990). Adaptive instruction: An alternative service delivery approach. Remedial \& Special Education, 11, 7-21.

White, L., Spurgeon, J., Jackson, P., \& Green-Folks, N. (Eds.). (1991). Cobb County School System Special Education Department procedures manual-collaborative teaching model-middle school pilot, 1991-92. Cobb County, GA: Cobb County School District.

Will, M. C. (1986). Educating children with learning problems: A shared responsibility. Exceptional Children, 52, 411-415. 


\section{Language Instruction for Students with Disabilities Second Edition}

Formerly Teaching Language Skills to Exceptional Learners

\section{Edward A. Polloway Lynchburg College}

This new book covers language development and disabilities, initial language training, and teaching the various language arts to exceptional children. Specific strategies for assessing and teaching language skills are detailed. It also addresses the important issue of cultural diversity.

The orientation is toward educational needs rather than clinical classifications. The discussion is current in terms of legislation, new research and practice. The range from mild to severe disabilities in language is covered.

You will find the coverage of language development, linguistic diversity, and disabilities in language functioning makes this book a perfect choice for your methods class.

\section{Tom E.C. Smith \\ University of Alabama \\ Birmingham}

\section{SPECIAL FEATURES}

Strong core chapters cover key background information necessary for understanding language instruction

Comprehensive discussion of the various language arts domains

Separate chapters on verbal and nonverbal communication

Entire chapter devoted to instruction for adolescents

Cultural diversity issues addressed

Current information on legislation, new research and practices
Contents

PART ONE: LANGUAGE AND STUDENTS WITH DISABILITIES

1 The Development of Language

2 Disabilities in Language

Functioning

3 Cultural Diversity and Language Differences

\section{PART TWO: INSTRUCTIONAL PROGRAMMING}

4 Principles of Assessment and Instruction

5 Initial Language Skills: Verbal

6 Initial Language Skills:

Nonverbal

7 Oral Language Skills

8 Reading: Nature and Assessment

9 Reading: Instruction

10 Handwriting Instruction

11 Spelling Instruction

12 Written Expression

13 Adolescents and Language Disabilities 


\section{INDEX • Volume 24}

Author Index

Paula J. Beckman (December 1991)

Harry L. Dangel (March 1992)

Randall F. Dobbs (October 1991)

E. Eugene Ensminger (March 1992)

Steven R. Forness (September 1991)

Steve Graham (February 1992)

Karen R. Harris (February 1992)

Dawn D. Hubbard (January 1992)

Janet W. Lerner (November 1991)

Sue R. Lerner (November 1991)

Joan Lieber (December 1991)

John W. Maag (September 1991)

Betsy Primm (October 1991)

Edith B. Primm (October 1991)

Robert Reid (February 1992)

Mark R. Shinn (January 1992)

Carol Westby (April 1992)

Alan E. White (May 1992)

Lynda L. White (May 1992)

\section{Chronological Index of Titles}

Depression in Children and Adolescents: Identification, Assessment, and Treatment (September 1991)

Mediation: A Common Sense Approach for Resolving Conflicts in Education (October 1991)

Attention Deficit Disorder: Issues and Questions (November 1991)

Social Coordination as a Component of Social Competence in Young Children with Disabilities (December 1991)

Curriculum-Based Measurement and Problem-Solving Assessment: Basic Procedures and Outcomes (January 1992)

Developing Self-Regulated Learners (February 1992)

The Foxfire Pedagogy: A Confluence of Best Practices for Special Education (March 1992)

Whole Language and Learners with Mild Handicaps (April 1992)

A Collaborative Model for Students with Mild Disabilities in Middle Schools (May 1992)

\section{PERMISSIONS AND COPYRIGHT}

All rights are reserved. No part of this publication may be reproduced, photocopied, faxed, stored in a retrieval system, or transmitted, in any form or by any means, electronic, mechanical, recording or otherwise, without the prior written permission of the publisher.
Back issues are available for sale. Reproduction requires permission and payment of fees. It is illegal and a violation of Federal copyright law to reproduce this publication without permission. Direct all inquiries to the permissions editor. 